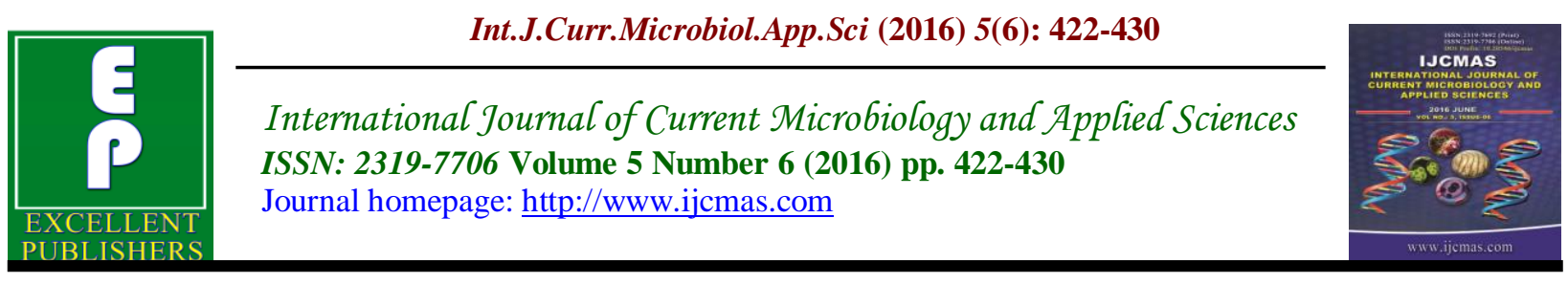

Original Research Article

http://dx.doi.org/10.20546/ijcmas.2016.506.049

\title{
Antibiogram Profile of Uropathogens in a Tertiary Care Hospital in Western Uttar Pradesh, India
}

\author{
Verma Devki*, Mohan Sneha and Chander Yogesh \\ Department of Microbiology, School of Medical Science and Research, Sharda University, \\ Greater Noida, Uttar Pradesh, India \\ *Corresponding author
}

\begin{abstract}
A B S T R A C T
Keywords

Uropathogens, antimicrobials, Kirby-Bauer disc diffusion test, urinary tract infections.

\section{Article Info}

Accepted:

20 May 2016

Available Online:

10 June 2016

The present study aims to study gender and age -wise distribution of UTIs, bacteriological profile of uropathogens, sensitivity pattern of the isolates and burden of multidrug resistant organisms including MRSA. Urine samples from suspected UTI cases were collected from June to November 2015. After direct microscopy the samples were cultured on CLED agar .Plates with significant growth were processed, and antibiotic susceptibility tested by Kirby Bauer disc diffuson method according to CLSI 2014 guidelines. Of the 1234 samples 329 showed significant growth. UTI was most common in females in the age-group 2140 years. The most common isolate was E.coli (44.68\%), followed by Klebsiella (24.62\%), CoNS (6.38\%) and Pseudomonas (5.78\%). Almost $100 \%$ gram negative organisms were sensitive to Nitrofurantoin and Imepenem and $100 \%$ gram positive cocci were sensitive to Vancomycin. $18.37 \%$ of the gram positive cocci were MRSA. Multidrug resistance was seen in $17.02 \%$ of uropathogens. The knowledge of antimicrobial pattern of routinely isolated uropathogens in any area provides guidance to clinicians in starting empirical treatment of UTI before laboratory reports are available.
\end{abstract}

\section{Introduction}

Urinary tract infections (UTI) are one of the most common bacterial infections seeking treatment in clinical practice. It is a serious health problem affecting millions of people each year. It is the most important cause of morbidity in the world affecting all age groups. One in five women develops a UTI during her lifetime. UTI in men are less common. Nearly, $20 \%$ of women who have a UTI will have another and $30 \%$ of those will have yet another episode of UTI.
In India, UTIs result in as many as 7 million visits to outpatient clinics, 1 million visits to emergency departments, and 100,000 hospitalizations annually (Razak et al., 2012). Worldwide, about 150 million people are diagnosed with UTI each year, costing the global economy in excess of 6 billion US dollars (Foxman et al., 2000).

Urinary tract infection (UTI) which is defined as presence and active multiplication of microorganisms within the 
urinary tract which is viewed as a single anatomical unit that is united by a continuous column of urine extending from the urethra to the kidney.

Although a variety of etiology is involved with UTI, $E$. coli and other coliforms account for large majority of naturally acquired urinary tract infections ( $\mathrm{v}$ et al., 1984). They are the frequent cause of nosocomial infections in many hospitals. Enterobacteriaceae and Escherichia coli in particular are the notorious pathogens (Naber et al., 2008) causing infections by adhering to, invading, and replicating the umbrella cells of the bladder epithelium .E. coli replication is facilitated by inflammation, leading to increased bacterial survival and invasion to the deeper layers of the urothelium. Consequently, these urothelial cells become reservoirs in which pathogens persist in a quiescent state becomes reservoirs and may be the source of recurrent UTIs.

Microorganisms causing UTI vary in their susceptibility to antimicrobials from place to place and time to time. Early detection and eradication of bacteriuria is very important for prevention of recurrence and complication eg chronic pyelonephritis, chronic renal failure etc. The extensive and inappropriate use of antimicrobial agents has invariably resulted in the development of antibiotic resistance which, in recent years, has become a major problem worldwide (Goldstein, 2000). In patients with suspected UTI, antibiotic treatment is usually started empirically, before urine culture results are available. To ensure appropriate treatment, knowledge of the organisms that cause UTI and their antibiotic susceptibility is mandatory.

The present study was undertaken to study the etiology and antibiogram of urinary tract infections among the patients attending Sharda Hospital.

\section{Materials and Methods}

\section{Study Design}

The study was conducted in the Department of Microbiology, School of Medical Sciences and Research and Sharda Hospital, Sharda University, Greater Noida, Uttar Pradesh, India, between June 2015 and November 2015. All the patients admitted in ICU with urinary catheter insertion for $>48$ hours were included in the study. All patients having symptoms of urinary tract infections were included in the study.

\section{Collection of Sample}

The patients were properly instructed on how to collect the sample and under aseptic conditions. Clean Catch Mid-stream specimen of urine was collected from each patient. In case of children the specimen was collected by suprapubic aspiration and was immediately transported to laboratory for further processing. Samples from catheters were taken by a sterile disposable syringe after cleaning and clamping the catheter tube. The name, age and sex were clearly mentioned on the universal container containing specimen.

\section{Direct Microscopy}

Wet mounts of urine were prepared and examined using both $10 \mathrm{X}$ and $40 \mathrm{X}$ objectives to look for the presence of pus cells, epithelial cells, red blood cells, crystals or Microorganisms. Pyuria was defined as presence of $\geq 10$ white blood cells $/ \mathrm{mm}^{3}$.

\section{Processing of Specimen/Culture}

A modified semi-quantitative technique using a standard bacteriological loop of urine was performed to transfer the $0.001 \mathrm{ml}$ 
of urine sample on CLED agar media. The plates were incubated at $37^{\circ} \mathrm{C}$ for $18-24 \mathrm{hrs}$. The plates were then examined macroscopically and microscopically for bacterial growth. The bacterial colonies were counted and multiplied by 1000 to give an estimate of the number of bacteria present per milliliter of urine. A significant bacterial count was taken as any count equal to or in excess of $10^{5} \mathrm{cfu} / \mathrm{ml}$.

\section{Identification of Isolates}

Pure isolates were identified using morphological, cultural and biochemical tests including Catalase test, Coagulase test, Indole Test, Triple Sugar Iron agar (TSI), citrate utilization test, Urease test, Methyl Red, VogesProskauer Test and Phenyl Pyruvic Acid test using the standard procedure for bacterial identification (Mackie and McCartney Practical Medical Microbiology, Tests for the identification of Bacteria). Isolates with equivocal biochemical reactions were confirmed by VITEK 2 Compact.

\section{Antibiotic susceptibility testing}

An antibiogram was done by Kirby Bauer agar disc diffusion technique according to the Clinical Laboratory Standards Institute (CLSI) guidelines (M100 S24, [2014]). Appropriate antibiotic discs were tested depending upon whether the organism was gram positive or gram negative. Interpretation of results was done based on the diameter of the zone.In this study multidrug resistance was defined as simultaneous resistance to three or more antimicrobial agents.

\section{Detection of Methicillin Resistant Staphylococcus aureus (MRSA)}

All the Staphylococcus aureus isolates were tested phenotypically for methicillin resistance by disc diffusion tests using $30 \mu \mathrm{g}$ cefoxitin. A zone diameter of $<19 \mathrm{~mm}$ were considered as MRSA (CLSI, 2014).

\section{Quality Control}

Reference strains E. coli (ATCC 25922) and $S$. Aureus (ATCC 25923) were used as a control reference strains for identifications and drug susceptibility testing. Negative control was done by randomly taking the prepared culture media and incubating over night to see for any growth.

\section{Results and Discussion}

During the study period, a total of 1234 urine samples of patients were collected and processed, of which $732(59.32 \%)$ were from females and $502(40.68 \%)$ were from males. Pathogenic bacteria (with significant bacterial growth $>10^{5} \mathrm{CFU} / \mathrm{ml}$ ) were isolated in 329 samples with prevalence rate of $26.67 \%$. The prevalence in females was $31.97 \%$ (234/732) and in males was $18.92 \%$ (95/502), as shown in Table 1.

UTI was most commonly seen in the age group of 21-40 years as it contained $55.62 \%$ (183/329) of the positive samples. The age wise distribution of the samples and their positivity is shown in Table 2. Among females UTI was commonly seen in the age group of 21-40 years and in males it was common between 41-60 years.

Gram negative bacilli 262 (79.64\%) were the predominant bacterial isolates. 147 isolates of E.coli were isolated and it was the most commonly isolated uropathogen (44.68 \%), followed by Klebsiella spp (24.62 \%) CoNS (6.38\%)and Pseudomonas (5.78\%). Among the non fermenters Pseudomonas was the most common. The isolation of all organisms are shown in Fig. 1 and Table 3. 
Antibiotic sensitivity pattern of the fermenter, non- fermenter and gram positive uropathogens is shown in Table 4 and Table 5 respectively. $100 \%$ of the Gram negative fermenter bacilli were sensitive to Imepenem, followed by Nitrofurantoin (93.31\%) and Amikacin (85.04\%). Maximum resistance was to the first and second generation Cephalosporins, Cephalothin (81.10\%) and Cefuroxime (76.38\%) respectively, followed by Ampicillin (73.62\%).Gram negative non fermenter bacilli showed maximum sensitivity to Nitrofurantoin (100\%), followed by Imepenem (96.15\%), Amikacin $(84.61 \%)$ and Norfloxacin (84.61\%). Maximum resistance was to Ceftazidime (61.54\%) followed by Astreonam (53.84\%) and Piperacillin (42.31\%).

Gram positive cocci showed maximum sensitivity to Vancomycin (100\%) followed by Teicoplanin (93.88\%) and Linezolid $(85.72 \%)$. Maximum resistance was to Penicillin (63.26\%) followed by Erythromycin $(42.85 \%)$.
Cefoxitin resistance was used to define MRSA. 9/17 S.aureus were MRSA. Thus, MRSA were $2.73 \%$ of all uropathogens.

Urinary tract infections are one of the most commonly diagnosed infections in our hospital and so probably in every hospital set up. The percent positivity for urinary cultures was found to be $26.67 \%$ (329 out of 1234 samples). An explanation behind such a low positive isolation rate may be that a majority of these patients presented with pyrexia and the urine culture formed a part of the septic work-up. A screening urinalysis like microscopy, dipstick or nitrate test which will detect Bacteriuria if done may help to choose only positive specimens to be sent for culture. Another reason for low prevalence could be large scale partial selfmedication due to easy availability of antibiotics over the counter. Similar findings were observed by Orrett F.A. et al., as well who reported an even lesser isolation rate of around $17 \%$ whereas in other reports by Akhar D.H et al., the authors have reported $44.29 \%$ isolation rate.

Table.1 Gender-wise distribution - Prevalence of Urinary Tract Infection

\begin{tabular}{|l|l|l|l|}
\hline Gender & Total no. of samples & No. of positives & Prevalence \\
\hline Females & 732 & 234 & $31.97 \%$ \\
\hline Males & 502 & 95 & $18.92 \%$ \\
\hline
\end{tabular}

The prevalence in females was almost double than in males

Table.2 Age Wise Distribution - Prevalence of Urinary Tract Infection

\begin{tabular}{|l|l|l|l|}
\hline Age (years) & $\begin{array}{c}\text { No. of positive } \\
\text { samples - Females }\end{array}$ & $\begin{array}{c}\text { No. of positive } \\
\text { samples - Males }\end{array}$ & Total \\
\hline$<20$ & 34 & 18 & 52 \\
\hline $21-40$ & 162 & 21 & 183 \\
\hline $41-60$ & 28 & 36 & 64 \\
\hline $61-80$ & 8 & 16 & 24 \\
\hline$>81$ & 2 & 4 & 6 \\
\hline \multicolumn{2}{|l}{ Maximum prevalence of UTI in third and forth decades }
\end{tabular}


Table.3 Distribution of isolates

\begin{tabular}{|l|c|c|}
\hline Microorganism & Number of isolates & Percentage \\
\hline E.coli & 147 & $44.68 \%$ \\
\hline Klebsiella & 81 & $24.62 \%$ \\
\hline CoNS & 21 & $6.38 \%$ \\
\hline Pseudomonas & 19 & $5.78 \%$ \\
\hline S.aureus & 17 & $5.17 \%$ \\
\hline Proteus & 13 & $3.95 \%$ \\
\hline Enterococcus & 11 & $3.34 \%$ \\
\hline Citrobacter & 9 & $2.73 \%$ \\
\hline Acinetobacter & 7 & $2.21 \%$ \\
\hline Enterobacter & 4 & $1.21 \%$ \\
\hline
\end{tabular}

E.coli and Klebsiella formed the majority of isolates.

Table.4 Antibiogram of gram negative bacilli

\begin{tabular}{|c|c|c|c|c|}
\hline \multirow[b]{2}{*}{ Antibiotic } & \multicolumn{2}{|c|}{ Fermenters (254) } & \multicolumn{2}{|c|}{ Non-Fermenters } \\
\hline & $\begin{array}{c}\text { No. of resistant } \\
\text { isolates }\end{array}$ & Resistant (\%) & $\begin{array}{l}\text { No. of resistant } \\
\text { isolates }\end{array}$ & Resistant $(\%)$ \\
\hline Ampicillin & 187 & $73.62 \%$ & - & - \\
\hline Amikacin & 38 & $14.96 \%$ & 4 & $15.38 \%$ \\
\hline Aztreonam & 147 & $57.87 \%$ & 14 & $53.84 \%$ \\
\hline $\begin{array}{l}\text { Amoxycillin/ } \\
\text { Clavulanic acid }\end{array}$ & 131 & $51.57 \%$ & - & - \\
\hline Cephalothin & 206 & $81.10 \%$ & - & - \\
\hline Cefuroxime & 194 & $76.38 \%$ & - & - \\
\hline Ceftriaxone & 131 & $51.57 \%$ & - & - \\
\hline Ceftazidime & 163 & $64.17 \%$ & 16 & $61.54 \%$ \\
\hline Cefepime & 119 & $46.85 \%$ & - & - \\
\hline Imipenem & 0 & 0 & 1 & $3.84 \%$ \\
\hline Levofloxacin & 86 & $33.86 \%$ & 9 & $34.61 \%$ \\
\hline Nitrofurantoin & 17 & $6.69 \%$ & 0 & $0 \%$ \\
\hline Norfloxacin & 137 & $53.94 \%$ & 4 & $15.38 \%$ \\
\hline Piperacillin & & & 11 & $42.31 \%$ \\
\hline $\begin{array}{l}\text { Piperacillin/ } \\
\text { Tazobactam }\end{array}$ & - & - & 7 & $26.92 \%$ \\
\hline Tetracycline & 142 & $55.91 \%$ & - & - \\
\hline Ticarcillin & 138 & $53.96 \%$ & 8 & $30.77 \%$ \\
\hline Tobramycin & 86 & $33.86 \%$ & 6 & $23.08 \%$ \\
\hline
\end{tabular}

Maximum sensitivity of gram negative bacilli (fermenters and non-fermenters) was to Imipenem, Nitrofurantoin and Amikacin. 
Table.5 Antibiogram of Gram positive cocci (total - 49)

\begin{tabular}{|l|c|c|c|c|}
\hline Antibiotic & $\begin{array}{l}\text { No. of isolates } \\
\text { sensitive }\end{array}$ & $\begin{array}{l}\text { Sensitive } \\
\text { (Percentage) }\end{array}$ & $\begin{array}{l}\text { No. of isolates } \\
\text { resistant }\end{array}$ & $\begin{array}{l}\text { Resistant } \\
\text { (Percentage) }\end{array}$ \\
\hline Amikacin & 37 & $75.51 \%$ & 12 & $24.49 \%$ \\
\hline Cefoxitin & 26 & $53.06 \%$ & 23 & $46.94 \%$ \\
\hline Clindamycin & 31 & $63.27 \%$ & 18 & $36.73 \%$ \\
\hline Ciprofloxacin & 40 & $81.63 \%$ & 21 & $18.37 \%$ \\
\hline Erythromycin & 28 & $57.15 \%$ & 12 & $42.85 \%$ \\
\hline Levofloxacin & 37 & $75.51 \%$ & 7 & $24.49 \%$ \\
\hline Linezolid & 42 & $85.72 \%$ & 0 & $0 \%$ \\
\hline Nitrofurantoin & 49 & $100 \%$ & 7 & $14.28 \%$ \\
\hline Norfloxacin & 42 & $85.72 \%$ & 31 & $63.26 \%$ \\
\hline Penicillin & 8 & $36.74 \%$ & 0 & $6.12 \%$ \\
\hline Teicoplanin & 46 & $93.88 \%$ & $100 \%$ & $0 \%$ \\
\hline Vancomycin & 49 & $100 \%$ & \\
\hline
\end{tabular}

Maximum sensitivity of gram positive cocci was to Vancomycin, Teicoplanin and Linezolid.

Fig.1 Isolation of various uropathogens

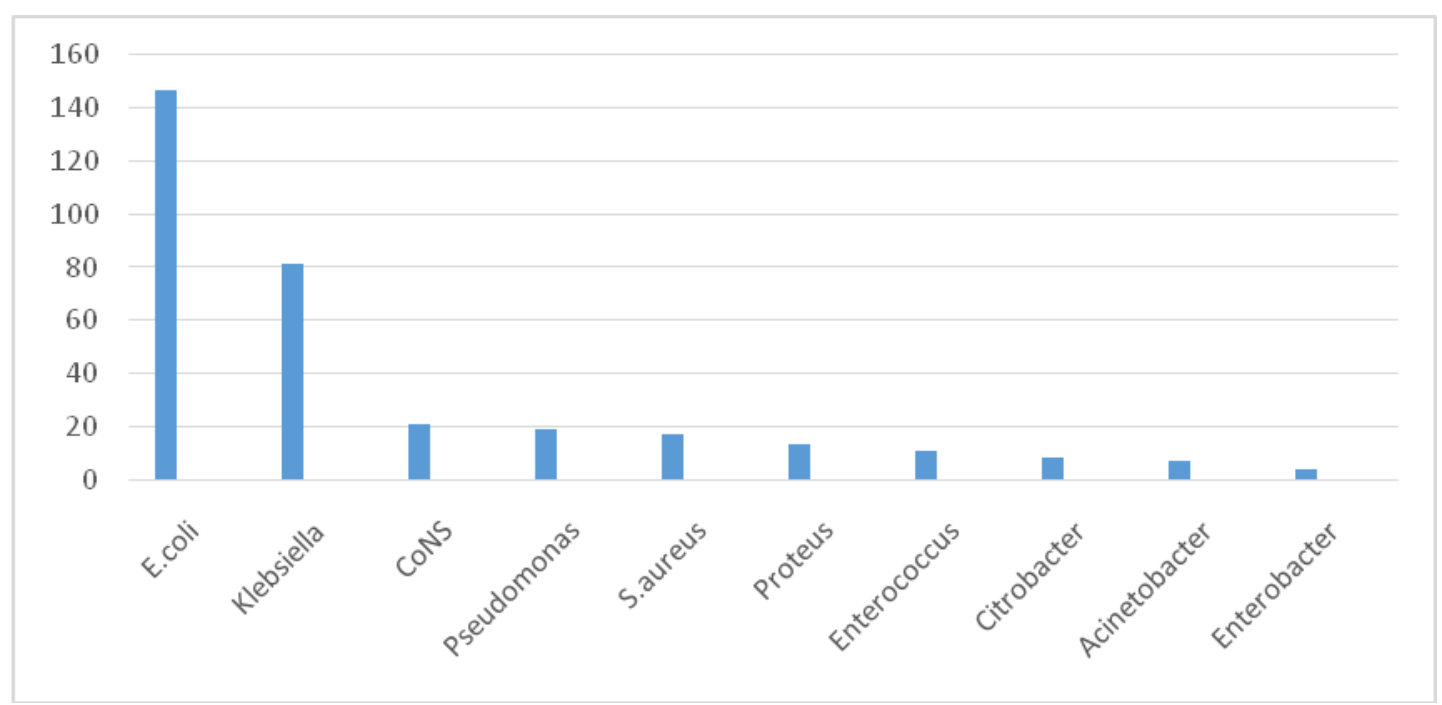

E.coli formed the majority of pathogens.

The prevalence of UTI was more in females than in males. Of the 329 isolates obtained, 234 were from females while 95 were from males. This is probably due to shorter and wider urethra of females (Jones, 1996). These results also agree with other reports like those of Akinyemi, et al., Burbige, et al., and Ibeawuchi R et al. which showed that UTIs are more frequent in females than males during adult hood
(Akinyemi et al., 1997; Ibeawuchi et al., 2002).

In females the incidence of UTI was found maximum in the age group of 21-40 followed by $<20$ and 41-60. In Males however, the age group of 41-60 formed the major group with UTI followed by 21-40, and $<20$ years with positive urine cultures. In females the incidence seen was more at 
an earlier age compared to that in males, where the incidence was more at more advanced age. In females the most common age group was of young sexually active females. This was in consistent with a study by Susan A.M.K. et al., who concluded that most uncomplicated urinary tract infections occur in women who are sexually active, with far fewer cases occurring in older women. In older men, the incidence of UTI may increase due to prostatic obstruction or subsequent instrumentation. In our study maximum urine culture positivity in male was in the 41-60 year age group $(37.89 \%$, $36 / 95$ ), which goes in accordance to the findings reported by Rao et al. (19). Similar findings were reported by Mbata Theodorein prison inmates in Nigeria.

UTIs are caused by a variety of microorganisms, including both gram positive and gram negative ones. The etiology of UTI has been regarded as well established \& reasonably consistent. In our study Escherichia coli (44.68\%) was predominant isolate followed by Klebsiella spp. (24.62\%) CoNS (6.38\%) and Pseudomonas aeruginosa (5.78\%) respectively. These findings agree with other reports which indicated that gram negative bacteria mostly E. coli and Klebsiella spp are the commonest pathogens isolated in patient with urinary tract infections (Banerjee, 2000; CLSI, 2014)

Antibiotic Susceptibility Test was performed by Kirby Bauer disc diffusion technique on bacterial isolates. The most useful antibiotics in this study were Imipenem, Cefepime, Amikacin and Nitrofurantoin. An alarming finding seen in the study was the substantial resistance shown to Ampicillin and first and second generation cephalosporins by a majority of the gram negative isolates. $2.73 \%$ of all uropathogens were MRSA. The possible explanation behind the resistance showed to the antibiotics, may be because these antibiotics have been in use for a long period and must have been abused and as a result the organisms must have developed mechanisms of circumventing their mode of action.

In conclusion, urinary tract infections (UTI) are one of the most common bacterial infections seeking treatment in clinical practice. Effective treatment of patients with UTIs commonly relies on the identification of the type of organisms and the selection of an effective antibiotic agent to the organism in question. The pattern of antimicrobial resistance of bacteria producing UTI varies in different regions. Monitoring of antimicrobial susceptibility can aid clinicians for prescribing appropriate antibiotics and in prevention of development of drug resistance (Beyene, 2011).

The study has shown that susceptibility pattern is necessary to obtain sensitivity reports before start of antibiotic treatment in cases of suspected UTI. The knowledge of antimicrobial pattern of routinely isolated uropathogens in that particular area may provide guidance to clinicians regarding the empirical treatment of UTI when therapy must be started before laboratory reports are available. We conclude that laboratories should encourage accurate bacteriological record keeping of urinary isolates and their antibiogram for better management of these cases.

\section{References}

Akhar, D.H. 2001. Urinary tract infections. Diabetics and Non-Diabetic patients. Saudi Med. J., 22: 326-9.

Akinyemi, K.O., Alabi, S.A., Taiwo, N.A., Omonighehin, E.A. 1997. Antimicrobial susceptibility pattern and plasmid profile of pathogenic bacteria isolated from subjects with 
urinary tract infections in Lagos, Nigeria. Nig. Qt. J. Hosp. Med., (1): 711.

Ashkenazi, S., EvenTov, S., Samra, Z., et al. 1991. Uropathogens of various childhood populations and their antibiotic susceptibility. Pediatr. Infect. Dis. J., 10: 742-6.

Banerjee, S. 2009. The Study Of Urinary Tract Infections And Antibiogram Of Uropathogens In And Around Ahmadnagar, Maharashtra.. The Internet J. Infect. Dis., Volume 9 Number 1.

Barnett, B.J., Stephens, D.S. 1997. Urinary tract infections: an over view. Am. J. Med. Sci., 314: 245-9.

Beyene, G., Tsegaye, W. 2011. Bacterial uropathogens in urinary tract infection and antibiotic susceptibility pattern in jimma university specialized hospital, southwest Ethiopia. Ethiop. J. Health Sci., 21: 141-6.

Bryan, C.S., K.L. Reynolds. 1984. J. Urol., 132: 490 .

Burbige, K.A., Retik, A.B., Colony, A., Bauer, S.B., Lebowitz, R. 1984. Urinary tract infection in boys. $J$. Urol., 132: 541-2

CLSI. Performance standards for antimicrobial susceptibility testing; twentieth informational supplement CLSI document M100-S20 Wayne, PA: Clinical and Laboratory Standards Institute 2014.

Ferri, C., Marchetti, F., Nickel, J.C., et al. 2005. Prevalence and clinical management of complicated urinary tract infection in Italy: a prospective multicenter epidemiological study in urological outpatients. J. Chemother., 17: $601-606$.

Foxman, B., Barlow, R., D'Arcy, H., et al. U2000. rinary tract infection: Selfreported incidence and associated costs. Ann. Epidemiol., 10: 509-15.
Goldstein, F.W. 2000. Antibiotic susceptibility of bacterial strains isolated from patients with community-acquired urinary tract infections in France. Multicentre Study Group. Eur. J. Clin. Microbiol. Infect. Dis., 19: 112-7.

Ibeawuchi, R,. Mbata, T.I. 2002. Rational and irrational use of antibiotics. Afri. Health, 24(2): 16-8.

Jones, R.N. 1996. Impact of changing pathogens and antimicrobial susceptibility pattern in treatment of serious infections in hospitalized patients. Am. J. Med., 100(Suppl.6A): S3 12.

Mackie and McCartney Practical Medical Microbiology. 2006. Tests for the identification of Bacteria 14th Edition, Delhi: Elsevier Publication, 131-50.

Magoha, G.A.O. 1997. Nosocomial infections of the urinary tract: patterns of antibiotic use and drug resistance. East Afr. Med. J., 74: 190-3.

Moges, A.F., Genetu, A., Mengistu, G. 2002. Antibiotic sensitivities of common bacterial pathogens in urinary tract infection at Gondar Hospital, Ethiopia, East Afr. Med. J., 79: 140-2.

Naber, K.G., G. Schito, H. Botto, J. Palou, T. Mazzei. 2008. Eur. Urol., 54: 1164-78.

Nassar, N.T. 2000. Management of urinary tract infections. J. Med. Liban, 79: 140-2.

National Committee for Clinical Lab Standards. 1993. Performance Standardization for Antimicrobial Disc Susceptibility test. 4th ed. Villanona PA. CC, DC M2 AS

Ojumba, U.C. 2005. Increasing incidence of bacterial resistance to antibiotics by isolates from the urinary tract. Niger J. Clin. Pract., 8: 107 -109. 
Orrett, F.A., Shurland, S.M. 1998. The changing pattern of antimicrobial susceptibility of urinary pathogens in Trininad. Singapore Med. J., 39(6): 256-9.

Rafay, A.M., Nsanze, H.N. 2003. Multi Drug resistance of Esch. coli from the urinary tract. Saudi Med. J., 24(3): 261 -4 .

Rao, B.N., Rao, P.A., Indira, M. 2007. Study of urinary tract infections with special reference to common bacterial isolates and their antibiogram in and around Visakhapatnam, Andhra Pradesh. The Indian Pract., Vol 60(6): 355-62.

Razak, S.K., Gurushantappa, V. 2012. Bacteriology of urinary tract infection and antibiotic susceptibility pattern in a tertiary care hospital in South India.
Int. J. Med. Sci. Public Health, 1: 10912.

Susan, A.M.K. 2005. Diagnosis and management of uncomplicated urinary tract infections. American Family Physician, 72(3): 451-6.

Turck, J.A., Stamm, W. 1981. Nososcomial infections of the urinary tract. Amer. J. Med., 70: 651-4.

Wagenlehner, F.M., Niemetz, A., Dalhoff, A., Naber, K.G. 2000. Spectrum and antibiotic resistance of uropathogens from hospitalized patients with urinary tract infection: 1ᄀ994 - 2000 Int. J. Antimicrob. Agents, 19: 557-64.

Wagenlehner, F.M., W. Weidner, K.G. Naber. 2005. Expert Opin. Emerg. Drugs., 10: 275-98.

\section{How to cite this article:}

Verma Devki, Mohan Sneha and Chander Yogesh. 2016. Antibiogram Profile of Uropathogens in a Tertiary Care Hospital in Western Uttar Pradesh, India. Int.J.Curr.Microbiol.App.Sci. 5(6): 422-430. doi: http://dx.doi.org/10.20546/ijcmas.2016.506.049 